\title{
High-Temperature Performance of Asphalt Mixtures: Preliminary Analysis for the Standard Technical Index Based on Gray Relational Analysis Method
}

\author{
Jian Xu $\mathbb{D}^{\mathbb{D}},{ }^{1}$ Yan Gong $\mathbb{D},{ }^{1}$ Li-Biao Chen, ${ }^{2}$ Tao $M a,{ }^{3}$ Jun-Cheng Zeng $\mathbb{D},{ }^{2}$ Er-Hu Yan $\mathbb{D},{ }^{1}$ \\ and Guang-Shu Xiao ${ }^{4}$ \\ ${ }^{1}$ Research Institute of Highway, Ministry of Transport, Beijing 100088, China \\ ${ }^{2}$ Fujian Expressway Construction Directorate, Fuzhou, Fujian 350001, China \\ ${ }^{3}$ Transportation College, Southeast University, Nanjing, Jiangsu 210096, China \\ ${ }^{4}$ Fujian Road and Bridge Construction Co., Ltd., Fuzhou, Fujian 350002, China
}

Correspondence should be addressed to Yan Gong; gy.1991@163.com

Received 13 July 2020; Revised 28 September 2020; Accepted 20 October 2020; Published 11 November 2020

Academic Editor: Meng Guo

Copyright $\odot 2020$ Jian Xu et al. This is an open access article distributed under the Creative Commons Attribution License, which permits unrestricted use, distribution, and reproduction in any medium, provided the original work is properly cited.

Aiming to evaluate the high-temperature performance of asphalt binders and asphalt mixtures and to investigate the reliability of the standard technical indexes to evaluate the performance of the asphalt, six typically used asphalt types were employed in this study. The standard high-temperature rheological test, the multiple stress creep recovery (MSCR) test, and the zero-shear viscosity (ZSV) test were employed to characterize the high-temperature performance and non-Newtonian fluid properties of the asphalt. Meanwhile, the high-temperature performance of the asphalt mixture was evaluated through the rutting tests based on the mixture design of AC-13. In general, the modified asphalt performed better than the unmodified asphalt according to the hightemperature rheological properties tests. The ranking of the six kinds of asphalt was confirmed to be different in various laboratory tests. The test results of the asphalt binders showed that the Tafpack Super- (TPS-) modified asphalt performed best in the MSCR and ZSV tests, while the low-grade asphalt PEN20 had the best technical indexes in the dynamic shear rheometer (DSR) test. Besides, the relation between the asphalt and the asphalt mixture was analyzed by gray relational analysis (GRA) method. The present rutting indicator $\left(G^{*} / \sin \delta\right.$ and $\left.G^{*} /\left(1-(\sin \delta \cdot \tan \delta)^{-1}\right)\right)$ for evaluating the asphalt mixtures' high-temperature performance might no longer be suitable. The Cross/Williamson model was the most suitable for calculating and fitting the ZSV, which could be used as the key indicator of the high-temperature performance evaluation of the asphalt. This work lays a foundation for the further study of the high-temperature performance evaluation of asphalt binders.

\section{Introduction}

At present, the Superpave asphalt performance evaluation system is widely used, which is a main outcome of the Strategic Highway Research Program (SHRP). In the Superpave specification, the shear complex modulus $\left(G^{*}\right)$, the phase angle $(\delta)$, and the rutting factor $\left(G^{*} / \sin \delta\right)$ from dynamic shear rheometer (DSR) test are used to evaluate the high-temperature mechanical performance of asphalt binders based on the law of energy dissipation and the rutting resistance [1-4]. For the base asphalt, some researches indicated that the rutting factor $\left(G^{*} / \sin \delta\right)$ had a good relation with the rutting resistance of the asphalt mixtures. However, for the modified asphalt, the applicability of traditional rutting factor $\left(G^{*} / \sin \delta\right)$ in the evaluation of high-temperature performance has been discussed over the years $[5,6]$. It was because, under the uninterrupted sinusoidal alternating loading in DSR test, the influence of the delayed elasticity was neglected, which played an important role in the deformation response of the modified asphalt [7]. In the research of National Cooperative Highway Research Program (NCHRP), the relational coefficient 
between the rutting factor and the permanent deformation rate of the mixture, measured by the repeated shear test (constant height) (RSCH), was only 0.23.

Recently, some new test methods and evaluation indexes have been proposed [8-11]. Considering the viscoelastic properties of asphalt, the elastic and viscous terms of shear complex modulus were defined, respectively. In the United States, Shenoy et al. $[12,13]$ put forward modified rutting factors $\left(G^{*} / 1-(\sin \delta \cdot \tan \delta)^{-1}\right)$ and $\left(G^{*} /(\sin \delta)^{9}\right)$ on the basis of the traditional rutting factor, which were proved to be more accurate in judging the rutting resistance of the modified asphalt. At the same time, the repeated creeprecovery test (RCRT) was suggested [14]. Based on RCRT, two new evaluation indexes in the multistress creep recovery (MSCR) test, percent deformation recovery $(R)$ and nonrecoverable deformation compliance $\left(J_{\mathrm{nr}}\right)$, were also proposed to solve the nonlinearity associated with the modified asphalt $[15,16]$. According to the AASHTO TP70 test method [17], two stress levels $(0.1$ and $3.2 \mathrm{kPa})$ were adopted as the test loads. The stress sensitivity indexes $\left(R_{\text {diff }}, J_{\mathrm{nr} \text {,diff }}\right)$ were also calculated from the difference in $R$ and $J_{\text {nr }}$ between two stress levels to evaluate the high-temperature performance of asphalt. Since the loading method in MSCR test takes into account the delayed elasticity of asphalt, this test method is applicable for predicting the high-temperature stability of both unmodified asphalt and polymer-modified asphalt [18-21], especially adopting higher stress load to simulate the actual situation $[22,23]$. Besides, the zero-shear viscosity (ZSV) test has attracted much attention in Europe. The polymer-modified asphalt is a typical non-Newtonian fluid at high temperatures, and the viscosity decreases with the increasing shear rate. Some researches found that the viscosity of the asphalt tended to have a stable value when the shear rate was very small or extremely large. Thus, in order to exclude the effect of shear rate on the test results, the zero-shear viscosity (ZSV) was proposed as an evaluation index to characterize rutting resistance of the asphalt, especially the polymer-modified asphalt $[2,24-26]$. Therefore, in this study, the ZSV and MSCR tests, as well as their technical indexes, were used for the high-temperature performance evaluations on both the base asphalt and modified asphalt.

Gray relation analysis (GRA) method has been applied in many fields to explain the problems of the uncertain systems with the multiple input, incomplete information and discrete data. In road engineering fields, it is indicated that GRA is applicable to research the performance of asphalt and its mixture [27]. Based on gray system approach, the relationship between composition of the asphalt and the service performance was analyzed to study the asphalt aging mechanism [28]. Wu et al. [29] predict normal incidence sound absorption coefficient and tire/road noise on asphalt pavements using the gray system model with Fourier residual correction. Zhang et al. [30] evaluated the effects of the regenerant's viscosity and acid value on the basic, rheological, and chemical properties of a typical rejuvenated asphalt by using GRA method. In Gao's work [31], the highest gray entropy relation between the dynamic viscosity of bioasphalt and the dynamic stability of the mixture provided a key index of bioasphalt's high-temperature performance evaluation. These results showed that GRA method could be considered as an alternative to the asphalt performance evaluation and mixture design analysis, of which the analysis results were accurate and reliable.

Although a lot of effort has been made to investigate high-temperature performance of various types of asphalt including the base asphalt binders and modifiers in recent years, the existing relationship models between the asphalt and its mixture still have application limitations and accuracy problems. Most of the existing literatures focus on the materials and properties evolution, instead of the development of technical indexes for characterizing the high-temperature performance of both the unmodified and modified asphalt mixtures. Therefore, aiming to evaluate the hightemperature performance of the asphalt binders and their mixtures and to investigate the relation between the performance indexes of the asphalt binders and their mixture, six typically used asphalt types (including three types belonging to base asphalt and three types belonging to polymer-modified asphalt) were employed in this study. The standard high-temperature rheological test, the MSCR test, and the ZSV test were employed to characterize the hightemperature performance. Meanwhile, the high-temperature performance of the asphalt mixture was evaluated through Marshall stability and rutting tests based on the mixture design of AC-13. Furthermore, the relation was determined by the gray relational analysis method. This study will provide a more systematic perspective for the further study of the high-temperature performance evaluation of asphalt binders.

\section{Materials}

2.1. Asphalt Binders. Because the applicability of the relationship between different kind of asphalt and asphalt mixture is controversial, the study is to investigate the reliability of the standard technical indexes to evaluate the performance of both the base asphalt and modified asphalt. Thus, in this study, three penetration grades of asphalt (PEN20, PEN50, and PEN90) and three types of polymermodified asphalt, which are two kinds of SBS- (styrenebutadiene-styrene-) modified asphalt named SBS I-C and SBS I-D (from Jiangsu Sinopec) and TPS- (Tafpack Super-) modified asphalt (from Gansu), were selected to investigate the high-temperature performance. The basic physical properties of six asphalt binders are shown in Table 1 . Note that since the TPS is a kind of new modifier, one of the objectives of the study is to compare the high-temperature performance of SBS-modified asphalt and that of TPSmodified asphalt.

2.2. Asphalt Mixture Design. In this study, the fine-grained continuous gradation asphalt concrete (AC-13) mixtures with the six kinds of asphalt binder were adopted for the high-temperature performance evaluations, according to the Chinese standard of JTG F40-2004 [32]. Table 2 shows the detailed gradation of AC-13. 
TABLE 1: The basic physical properties of six asphalt binders.

\begin{tabular}{|c|c|c|c|c|c|c|}
\hline \multicolumn{2}{|c|}{ Asphalt binders } & $\begin{array}{c}\text { Penetration }\left(25^{\circ} \mathrm{C}, 100 \mathrm{~g}, 5 \mathrm{~g}\right) \\
0.1 \mathrm{~mm}\end{array}$ & $\begin{array}{l}\text { Penetration index } n / \\
a\end{array}$ & $\begin{array}{l}\text { Softening point, } \\
{ }^{\circ} \mathrm{C}\end{array}$ & $\begin{array}{l}\text { Ductility }\left(5 / 15^{\circ} \mathrm{C}\right) \text {, } \\
\mathrm{cm}\end{array}$ & $\begin{array}{l}\text { Viscosity } \\
\left(60^{\circ} \mathrm{C}\right), \mathrm{Pa} \cdot \mathrm{s}\end{array}$ \\
\hline \multirow{3}{*}{ Unmodified } & PEN20 & 23 & 0.81 & 64.2 & $10 / 62$ & 3315.2 \\
\hline & PEN50 & 54 & 0.29 & 52.4 & $1 / 87$ & 393.8 \\
\hline & PEN90 & 91 & -0.94 & 47.7 & $0.5 />100$ & 198 \\
\hline \multirow{3}{*}{ Modified } & SBS I-C & 74 & 0.03 & 66.0 & $56 />100$ & 27360 \\
\hline & SBS I-D & 57 & -0.05 & 66.9 & $26 />100$ & 49755 \\
\hline & TPS & 69 & 0.89 & 80.7 & $38 />100$ & 82459 \\
\hline
\end{tabular}

Note that the date of ductility before " $"$ " was tested at $5{ }^{\circ} \mathrm{C}$, and date of ductility after " " was tested at $15^{\circ} \mathrm{C}$.

TABLe 2: Gradation of aggregate for AC-13.

\begin{tabular}{|c|c|c|c|c|c|c|c|c|c|}
\hline Sieve size, $\mathrm{mm}$ & 13.2 & 9.5 & 4.75 & 2.36 & 1.18 & 0.6 & 0.3 & 0.15 & 0.075 \\
\hline Selected (\%) & 97 & 82 & 47 & 31 & 21.5 & 15 & 11 & 8 & 6 \\
\hline Upper (\%) & 100 & 85 & 68 & 50 & 38 & 28 & 20 & 15 & 8 \\
\hline Lower (\%) & 90 & 68 & 38 & 24 & 15 & 10 & 7 & 5 & 4 \\
\hline Intermediate $(\%)$ & 95 & 76.5 & 53 & 37 & 26.5 & 19 & 13.5 & 10 & 6 \\
\hline
\end{tabular}

Based on the gradation of aggregate for AC-13 mixtures, different asphalt contents were selected for applying in the Marshall test to determine the optimum asphalt content (OAC) of the six kinds of asphalt binder. According to the Chinese standard of JTG F40-2004 [32], the testing data of the asphalt mixture Marshall specimen are shown in Table 3, including the asphalt-aggregate ratio, the apparent density, the theoretical maximum density, the air void (VV), the voids in mineral aggregate (VMA), and the voids filled with asphalt (VFA). The Marshall tests mentioned earlier were based on the SBS-modified asphalt binder. The air void (VV) of the Marshall specimen could be calculated through measuring the apparent density and the theoretical maximum density. In order to ensure that the air void of the Marshall specimen was around $4 \%$, the different asphalt binders had various OACs. The final determined OAC of AC-13 mixtures in the study was $4.6 \mathrm{wt} \%$ for PEN50 and PEN90 asphalt binder, $4.8 \mathrm{wt} \%$ for PEN20 asphalt binder, $4.9 \mathrm{wt} \%$ for SBS-modified asphalt binder, and $5.1 \mathrm{wt} \%$ for TPS-modified asphalt binder, respectively.

\section{Testing Methods and Analysis Models}

3.1. DSR Test. DSR tests were performed in accordance with the method specified in AASHTO T315 [33]. The complex modulus $G^{*}$, the phase angle $\delta$, and the rutting indicator $\left(G^{*} / \sin \delta\right)$ were obtained on the virgin asphalt binder samples (except for the correlation analysis in Section 4.3) via Kinexus Ultra+ (Malvern Panalytical) DSR at $64^{\circ} \mathrm{C}, 70^{\circ} \mathrm{C}$, $76^{\circ} \mathrm{C}, 82^{\circ} \mathrm{C}$, and $88^{\circ} \mathrm{C}$, with the sample diameter of $25 \mathrm{~mm}$ and the thickness of $1 \mathrm{~mm}$. The loading frequency in the DSR tests was $10 \mathrm{rad} / \mathrm{s}$. For the correlation analysis, the DSR tests were conducted on both the unaged asphalt and the aged asphalt (rolling thin film oven test (RTFOT)). Three repeated tests were employed to ensure the reliability of the results.

3.2. MSCR Test. MSCR tests were performed on Kinexus Ultra+ (Malvern Panalytical) DSR at $64^{\circ} \mathrm{C}, 70^{\circ} \mathrm{C}, 76^{\circ} \mathrm{C}, 82^{\circ} \mathrm{C}$, and $88^{\circ} \mathrm{C}$. The sample was the rolling thin film oven test (RTFOT) residue of asphalt binder, which is applied to simulate the short-term aging condition of asphalt. The percent recovery and nonrecoverable creep compliance were obtained by applying a continuous cyclic load to the samples, with the sample diameter of $25 \mathrm{~mm}$ and the thickness of $1 \mathrm{~mm}$. Each creep recovery cycle consisted of a stress loading period ( $1 s)$ and then a zero-stress recovery period ( $9 s)$. The test process was under two stress levels $(0.1$ and $3.2 \mathrm{kPa})$. The first 20 cycles of creep recovery were conducted under the shear load stress of $0.1 \mathrm{kPa}$, followed by additional 10 cycles under $3.2 \mathrm{kPa}$. Besides, the RTFOT were conducted at $163^{\circ} \mathrm{C}$ for $85 \mathrm{~min}$ [34]. It is worth noting that three repeated tests were carried out on each type of asphalt binder to ensure the reliability of the results.

3.3. ZSV Test. ZSV tests were performed on Kinexus Ultra+ (Malvern Panalytical) DSR at the test temperature of $60^{\circ} \mathrm{C}$. The sample was the rolling thin film oven test (RTFOT) residue of asphalt binder, with the same diameter and thickness as those of the samples in MSCR tests $(25 \mathrm{~mm}$ and $1 \mathrm{~mm})$. The steady-state flow test was used to determine the viscosity at different shear frequencies, which ranged from 10 to $0.01 \mathrm{rad} / \mathrm{s}$. Then the zero-shear viscosity (ZSV) was calculated by the shear rheological fitting curve. For each type of asphalt binder, at least ten repeated tests were conducted within each order of magnitude to ensure the reliability. At present, the commonly used fitting models, which were used to calculate the value of ZSV, include the Cross/Sybilski model, Cross/Williamson model, and Carreau model. The Cross/Sybilski model, Cross/Williamson model, and Carreau model were expressed as follows:

$$
\begin{array}{r}
\frac{\eta}{\eta_{0}}=\frac{1}{1+(K \omega)^{m}}, \\
\frac{\eta-\eta_{\infty}}{\eta_{0}-\eta_{\infty}}=\frac{1}{1+(K \omega)^{m}},
\end{array}
$$


TABle 3: Testing data of the asphalt mixture Marshall specimen.

\begin{tabular}{|c|c|c|c|c|c|c|c|}
\hline \multicolumn{2}{|c|}{ Asphalt binders } & $\begin{array}{c}\text { Asphalt-aggregate ratio } \\
\%\end{array}$ & $\begin{array}{l}\text { Apparent density } \\
\mathrm{g} / \mathrm{cm}^{3}\end{array}$ & $\begin{array}{l}\text { Theoretical maximum density } \\
\mathrm{g} / \mathrm{cm}^{3}\end{array}$ & $\begin{array}{l}\mathrm{VV} \\
\%\end{array}$ & $\begin{array}{l}\text { VMA } \\
\%\end{array}$ & $\begin{array}{c}\text { VFA } \\
\%\end{array}$ \\
\hline \multirow{3}{*}{ Unmodified } & PEN20 & 4.8 & 2.431 & 2.542 & 4.35 & 14.28 & 69.5 \\
\hline & PEN50 & 4.6 & 2.433 & 2.547 & 4.42 & 14.21 & 68.7 \\
\hline & PEN90 & 4.6 & 2.437 & 2.553 & 4.55 & 14.11 & 67.8 \\
\hline \multirow{3}{*}{ Modified } & SBS I-C & 4.9 & 2.414 & 2.522 & 4.30 & 14.83 & 71 \\
\hline & SBS I-D & 4.9 & 2.419 & 2.528 & 4.33 & 14.66 & 70.5 \\
\hline & TPS & 5.1 & 2.409 & 2.516 & 4.25 & 14.97 & 71.6 \\
\hline
\end{tabular}

$$
\frac{\eta-\eta_{\infty}}{\eta_{0}-\eta_{\infty}}=\frac{1}{\left[1+(K \omega)^{2}\right]^{(m / 2)}}
$$

Equation (1) was for the Cross/Sybilski model, equation (2) was for the Cross/Williamson model, and equation (3) was for the Carreau model. $\eta$ was the complex viscosity of the asphalt sample, $\eta_{0}$ was the ZSV of the asphalt sample, and $\eta_{\infty}$ was the complex viscosity when the shear frequency is infinite. Note that the value of $\eta_{\infty}$ cannot be directly obtained from the tests and was replaced with the complex viscosity at $10 \mathrm{rad} / \mathrm{s}$. $K$ and $m$ are the property coefficients of the asphalt sample.

The accelerated loading facility test in the United States showed that the Carreau model was more suitable than the Cross/Williamson model for calculating the value of ZSV. In this paper, the three models were all adopted and compared to characterize rutting resistance of the asphalt sample better.

3.4. Rutting Test. In order to evaluate the high-temperature performance of the asphalt mixtures, the rutting test adopted in this paper was carried out in accordance with the method specified in the Chinese standard of JTG E20-2011 [35]. The test pieces of asphalt mixture should have the size of $300 \times 300 \times 50(L \times b \times h) \mathrm{mm}^{3}$. The rutting formed on the test piece surface under the repeated passing action of the wheel along the same trajectory at a frequency of $42 \pm 1$ cycles/min. The dynamic stability (DS) of the test piece was calculated, as shown in the following equation:

$$
\mathrm{DS}=\frac{\left(t_{2}-t_{1}\right) \times N}{d_{2}-d_{1}},
$$

where $d_{1}$ and $d_{2}$ were the rutting depths at $t_{1}(45 \mathrm{~min})$ and $t_{2}$ (60 min), respectively. $N$ was the frequency of the wheel passing through the test pieces. The antirutting property of asphalt mixture was evaluated by the dynamic stability. It is worth noting that three repeated tests were carried out on each type of asphalt binder to ensure the reliability of the results.

3.5. GRA Method. Gray relational analysis (GRA) method is a mathematical analysis method to measure the relationship between the factors and the system behaviors based on the finite and irregular data $[36,37]$. In the principle of GRA, the relation among the data array curves is usually judged based on the similarity among geometric shapes. The gray relational coefficient can be calculated quantitatively by the normalization and comparison of the data arrays. The gray relational degree is subsequently calculated by taking the arithmetic average of the gray relational coefficients at different time point. A larger relational degree means a higher similarity among the data.

The detailed calculating methods of the gray relational coefficient and gray relational degree are as follows.

Suppose that there was a matrix, composed of a series of data arrays:

$$
\begin{array}{ll}
\left\{X_{0}^{(0)}(r)\right\}, & r=1,2,3, \ldots, n, \\
\left\{X_{1}^{(0)}(r)\right\}, & r=1,2,3, \ldots, n, \\
\left\{X_{2}^{(0)}(r)\right\}, & r=1,2,3, \ldots, n, \\
& \ldots \\
\left\{X_{k}^{(0)}(r)\right\}, & r=1,2,3, \ldots, n .
\end{array}
$$

$X$ was the gray relational factor set, and the $k$ arrays were $k$ factors. $n$ was the dimension of different $k$ factors, which was the same value in this paper. $X_{0}^{(0)}$ was the main array (or the reference array) and $X_{m}^{(0)}(m=1,2,3, \ldots, k)$ were the subarrays (or the comparison arrays).

As different values in the matrix have a great difference, the normalization of the arrays is necessary for comparing different factors directly and eliminating the dimension divergence. In this paper, the equalization method was utilized for normalizing treatment. The main array and the subarrays were processed as follows:

$$
\begin{aligned}
\left\{X_{m}^{(1)}(r)\right\} & =\frac{\left\{X_{m}^{(0)}(r)\right\}}{\overline{X_{m}}}, \\
\overline{X_{m}} & =\frac{1}{N_{m}}\left\{\sum_{r=1}^{N_{m}} X_{m}^{(0)}(r)\right\} .
\end{aligned}
$$

$X_{m}^{(1)}(m=0,1,2,3, \ldots, k)$ were the normalized arrays and $\frac{m}{X_{m}}$ was the arithmetic average value of the original arrays. 
The gray relational coefficient $\left(\gamma_{m}(r)\right)$ between $X_{0}^{(0)}$ and $X_{m}^{(0)}$ was expressed as follows:

$$
\gamma_{m}(r)=\frac{\min _{(m)} \min _{(r)}\left|X_{0}^{(1)}(r)-X_{m}^{(1)}(r)\right|+\xi \max _{(m)} \max _{(r)}\left|X_{0}^{(1)}(r)-X_{m}^{(1)}(r)\right|}{\left|X_{0}^{(1)}(r)-X_{m}^{(1)}(r)\right|+\xi \max _{(m)} \max _{(r)}\left|X_{0}^{(1)}(r)-X_{m}^{(1)}(r)\right|} .
$$

The gray relational degree $\left(\Gamma_{m}\right)$ indicated the relational degree between the main array and the subarrays, which was calculated as follows:

$$
\Gamma_{m}=\sum_{r=1}^{n} \beta_{r} \gamma_{m}(r)
$$

and $\xi$ was the distinguishing coefficient, which was 0.2 in this paper [31], according to the previous research. $\beta_{r}$ was the weighting of gray relational coefficient.

Gray relational entropy is a kind of gray entropy to characterize the distances between the points and each reference point. The density value of distribution of the subarrays $\left(P_{m}\right)$ was calculated as follows:

$$
R_{m}=\left\{\gamma_{m}(r)\right\}, \quad r=1,2,3, \ldots, n ; m=0,1,2,3, \ldots, k,
$$

$$
P_{m} \triangleq \frac{\gamma_{m}(r)}{\sum_{r=1}^{n} \gamma_{m}(r)}, \quad m=0,1,2,3, \ldots, k
$$

$H\left(R_{m}\right) \triangleq \sum_{r=1}^{n} P_{m} I n P_{m}, \quad m=0,1,2,3, \ldots, k$

$R_{m}$ is a matrix composed of the gray relational coefficient $\left(\gamma_{m}(r)\right)$. The gray relational entropy of the sequence $X_{m}$ was introduced as follows:

The entropy relational degree $E(X m)$ of the sequence $X_{m}$ was calculated as follows:

$$
E\left(X_{m}\right) \triangleq \frac{H\left(R_{m}\right)}{H_{m}}
$$

where $H_{m}$ was the maximum value of the gray relational entropy.

The entropy relational degree was used to characterize the correlation between the subarrays and the main arrays. The larger the gray relational degree of the sequence $X_{m}$ was, the closer the geometry of the sequence $X_{m}$ to that of the reference sequence would be. Therefore, using the GRA model, the degree of correlation between the high-temperature performance of asphalt binders and the dynamic stability of the mixtures was determined.

When studying the relationship between the asphalt and mixture, the steps used to calculate the gray correlation degree and the entropy relational degree are listed as follows. Firstly, the test results of asphalt binders, including the penetration, softening point, viscosity, rutting factor, modified rutting factor, percent recovery, nonrecoverable creep compliance, and zero-shear viscosity, were the subarrays. The DS of asphalt mixtures was the main array. Then, the main array and subarrays were both normalized. Finally, the gray relational coefficients and gray relational degree could be calculated according to equations (8) (13).

\section{Results and Discussion}

\subsection{High-Temperature Rheological Properties of Asphalt}

4.1.1. DSR Test Results. The high-temperature rheological properties of six asphalt binders including the complex modulus $G^{*}$, the phase angle $\delta$, and the rutting indicator $\left(G^{*} / \sin \delta\right)$ are shown in Figure 1, respectively. The hightemperature grades of the polymer-modified asphalt were $82,70,64,76,82$, and $82^{\circ} \mathrm{C}$ for PEN20, PEN50, PEN90, SBS I-C, SBS I-C, and TPS-modified asphalt. It was found that the phase angle curves had different forms in Figure 1(b), which was related to whether the modifiers were added and the properties of various modifiers. For the unmodified asphalt, the phase angle curves both rose with the increasing of the temperature. Meanwhile, for the modified asphalt, the trend of rising had slowed down, and there was a certain degree of decline in the temperature range of $76-88^{\circ} \mathrm{C}$. The phase angle was an important feature to characterize the viscosity change of asphalt under the external shear force, which reflected that the addition of SBS and TPS was beneficial for the asphalt to maintain a relatively good shear strain recovery ability at higher temperatures. Among them, TPS-modified asphalt was the preferred except in the temperature range of $82-88^{\circ} \mathrm{C}$, at which SBS I-D-modified asphalt had the smaller phase angle.

Besides, as shown in Figures 1(a) and 1(c), the complex modulus $G^{*}$ and the rutting indicator $\left(G^{*} / \sin \delta\right)$ value of low-grade asphalt PEN20 were significantly larger than the other five kinds of asphalt in the interval of $64-82^{\circ} \mathrm{C}$. When the temperature was higher than $82^{\circ} \mathrm{C}$, the rutting indicator $\left(G^{*} / \sin \delta\right)$ of TPS-modified asphalt was the best, while the high-temperature performances of PEN90 and PEN50 asphalt were always weak. The rheological properties of the six kinds of asphalt at the PG grade temperatures were summarized in Figure 1(d). It can be observed that the SBS I-D presented the lowest complex modulus $G^{*}$ and rutting indicator $\left(G^{*} / \sin \delta\right)$, and PEN20 had the largest phase angle $\delta$. Since the difference between the SBS I-D and TPS-modified asphalt was less than 20\%, TPS had similar high-temperature responses to SBS, and it could be considered for replacing the traditional SBS with proper regard to the high-temperature performances. 


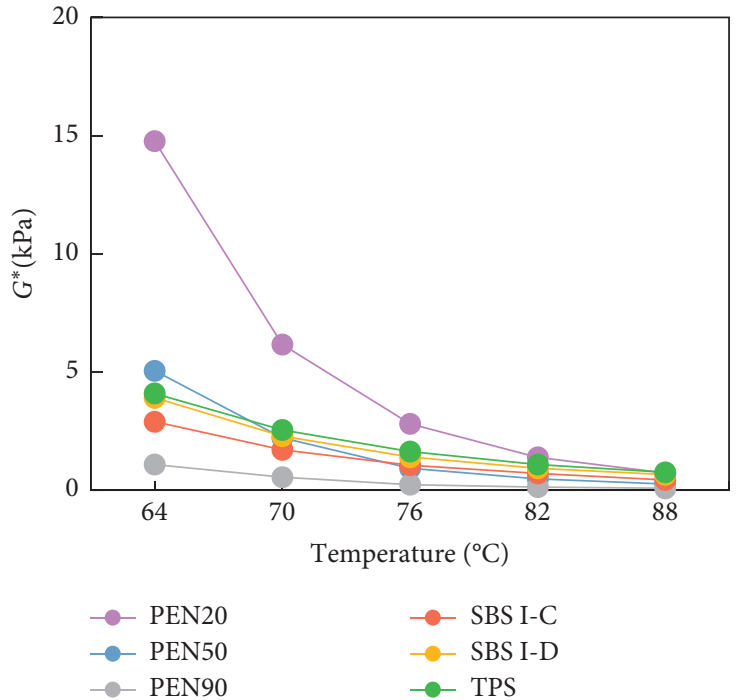

(a)

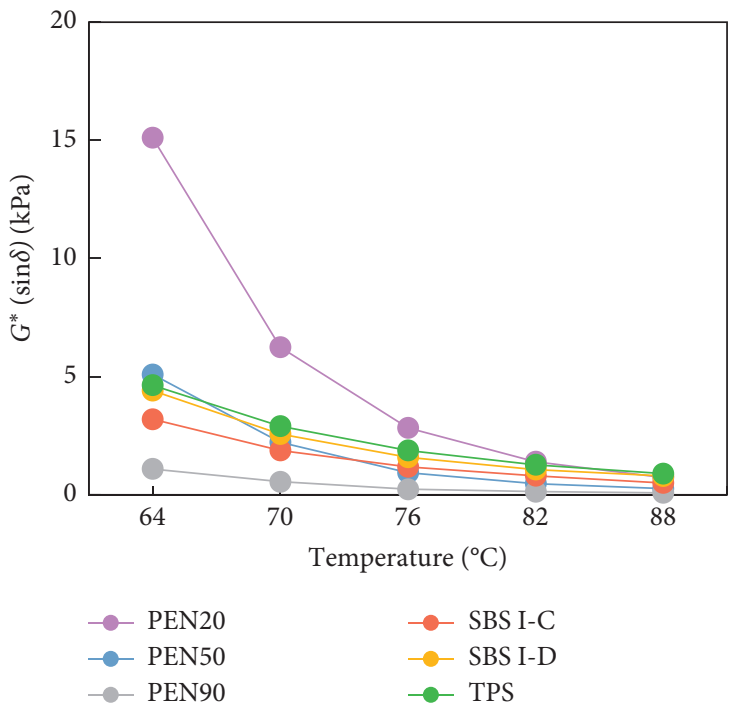

(c)

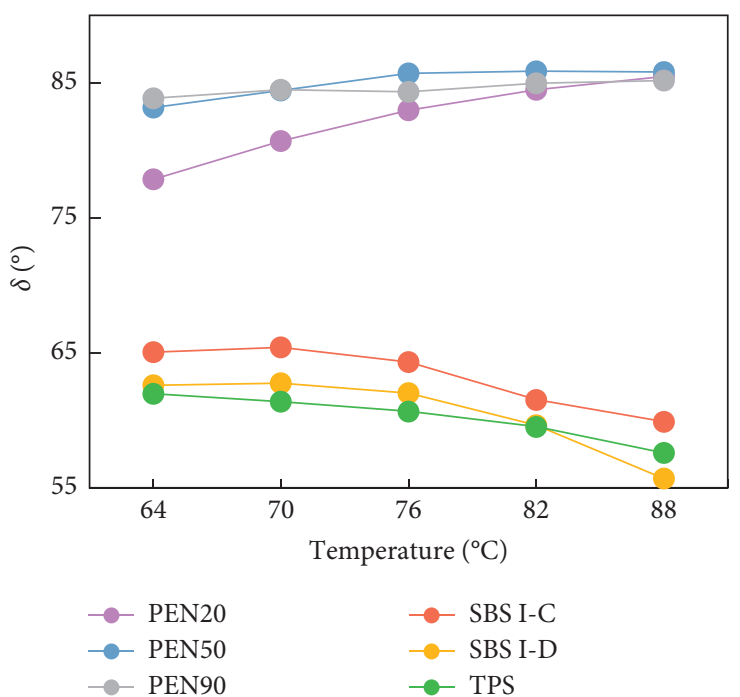

(b)

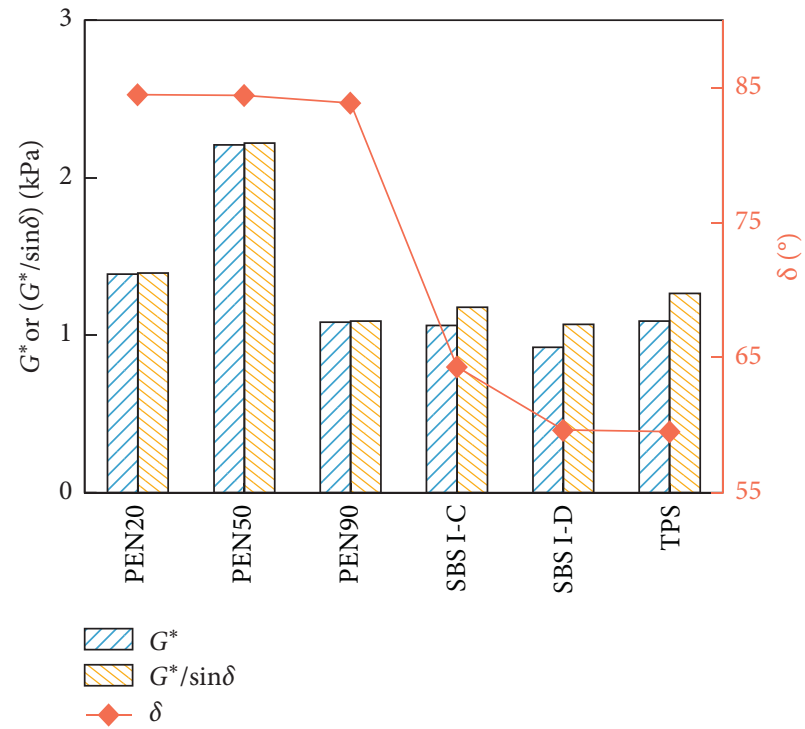

(d)

FIgURE 1: High-temperature rheological properties of six asphalt binders: (a) complex modulus, (b) phase angles, (c) rutting indicator, and (d) rheological parameters at the PG grade temperatures.

4.1.2. MSCR Test Results. The MSCR test results of the six asphalt binders at different temperature are shown in Figure 2. These results indicated the significant viscoelasticplastic properties of the asphalt. Figure 2(a) illustrates the nonrecoverable deformation compliance $J_{\mathrm{nr}}$ of the six asphalt binders at $3.2 \mathrm{kPa}$. It could be found that the nonrecoverable deformation compliance $J_{\text {nr }}$ values all had an exponential relationship with the temperature, indicating that the high-temperature stability of asphalt would be significantly weakened as the temperature increased. The difference in $J_{\mathrm{nr}}$ between two stress levels $(0.1 \mathrm{kPa}$ and $3.2 \mathrm{kPa}$ ) was an important indicator to evaluate the hightemperature performance related to the external stress response. The larger $J_{\text {nrdiff }}$ value indicated the greater stress sensitivity of the resistance to cumulative deformation. As shown in Figure 2(b), TPS-modified asphalt showed the greatest stress sensitivity, followed by SBS I-D-modified asphalt. It was concluded that the modified asphalt had greater stress sensitivity of the resistance to cumulative deformation than the base asphalt.

Figure 2(c) shows the creep and recovery rate of the asphalt at $3.2 \mathrm{kPa}$. The curves had different forms, which were automatically divided into two shapes according to whether the modifiers were added. Under the creep load condition, the PEN90 asphalt had a significant degree of deformation and a low deformation recovery rate, which indicated that the PEN90 asphalt performed soft viscosities compared with the other types of asphalt. Note that the $R_{3.2}$ value of the PEN90 asphalt was lower than zero, indicating that the destruction of the structure made the asphalt 


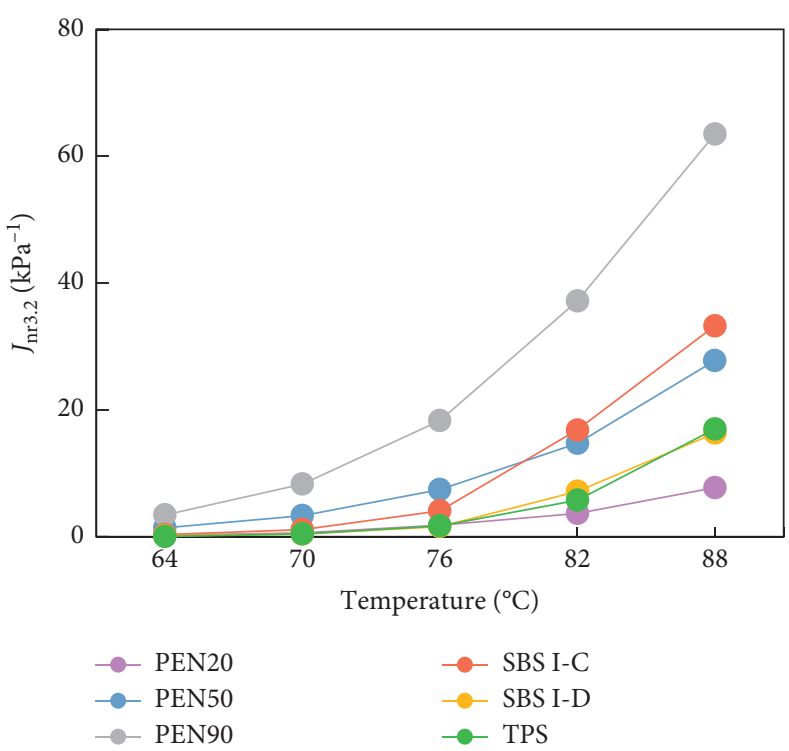

(a)

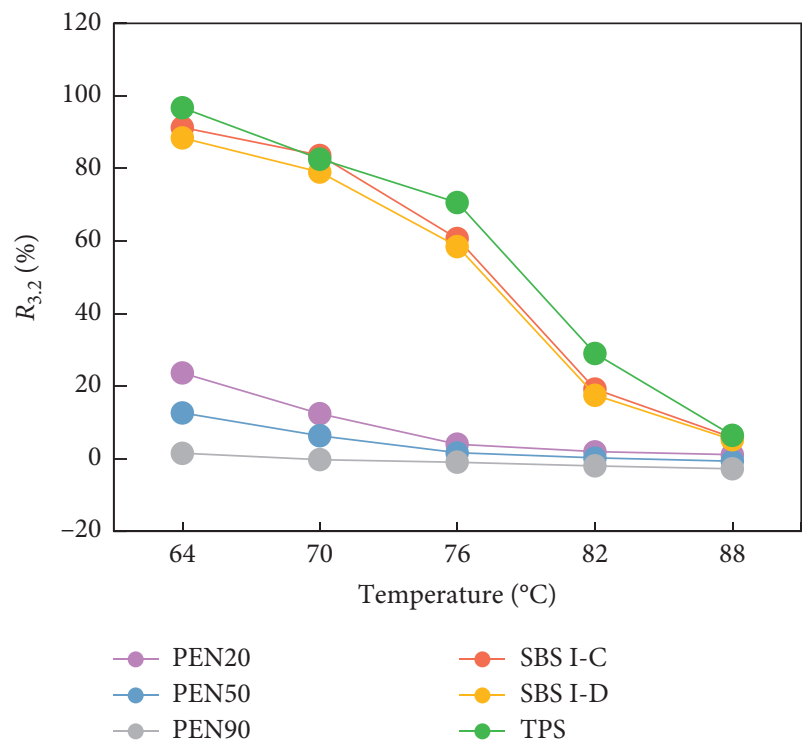

(c)

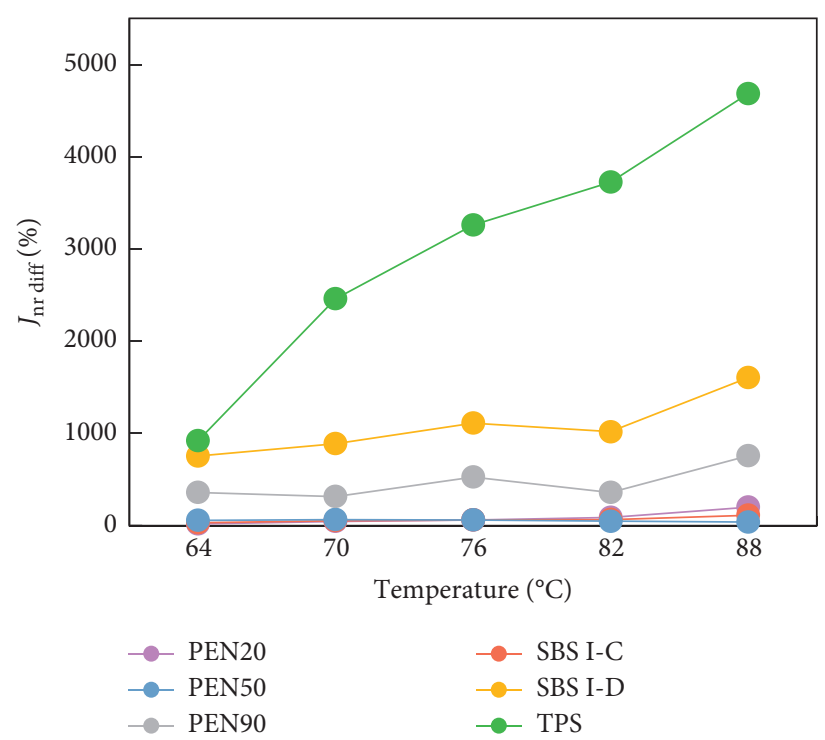

(b)

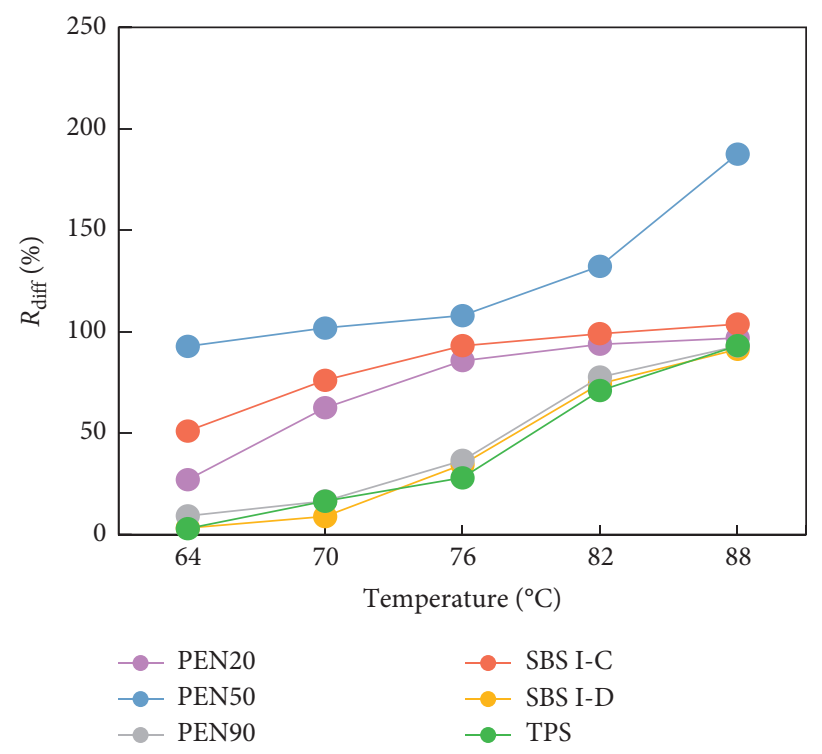

(d)

FIGURE 2: Multiple stress creep recovery (MSCR) test results of six asphalt binders.

completely lose its elasticity and become a fluid. Figure 2(d) shows the change in the stress sensitivity index $R_{\text {diff }}$ of the asphalt with temperature. The large $R_{\text {diff }}$ value indicated the recovery capability of asphalt was sensitive to the applied stress. It was reconfirmed that the six asphalt binders all exhibited greater sensitivity to the stress at the high temperature, as shown in Figure 2(b). Generally speaking, the TPS-modified asphalt performed best in the MSCR test, followed by the SBS I-D-modified asphalt, because they had the least deformation and the most substantial deformation recovery ability. It is worth noting that the low-grade PEN20 asphalt also had the low deformation, while its deformation recovery ability was poor.
4.1.3. ZSV Test Results. The ZSV test results of the six asphalt binders at $60^{\circ} \mathrm{C}$ are shown in Figure 3 as well as the complex viscosity $\eta$-frequency $\omega$ curves, the fitted $K, m$, and ZSV values using the Cross/Sybilski model, Cross/Williamson model, and Carreau model.

As shown in Figure 3, there were substantial differences in $K, m$, and ZSV values between different kinds of asphalt using three different models, especially the base asphalt and modified asphalt. In order to present the data more clearly and in detail, the standard deviation $\sigma$ for data is shown in Table 4.

It has been proved that the parameter $m$ mainly reflected the sensitivity of the asphalt to shear stress, and the closer the 


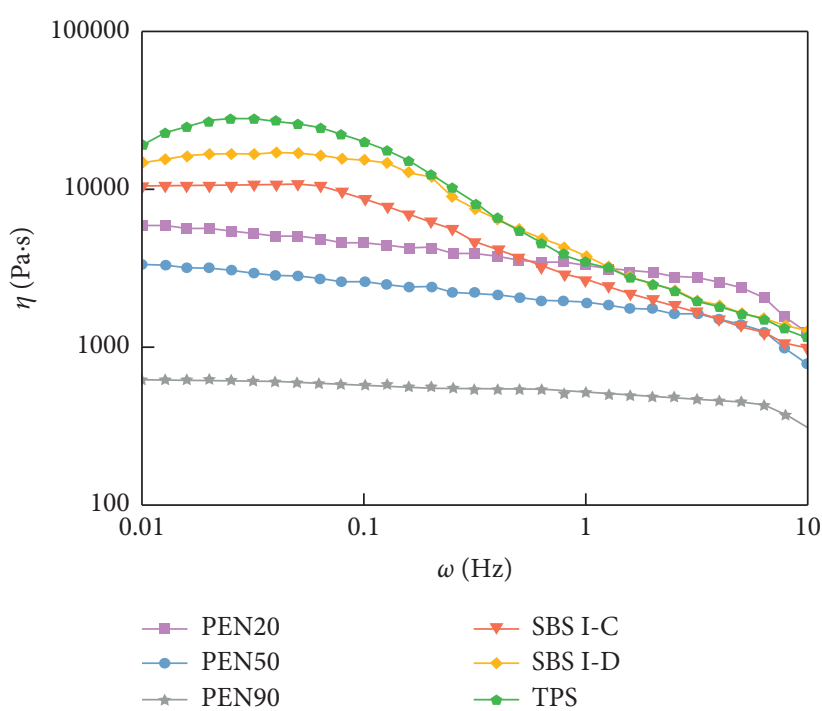

(a)

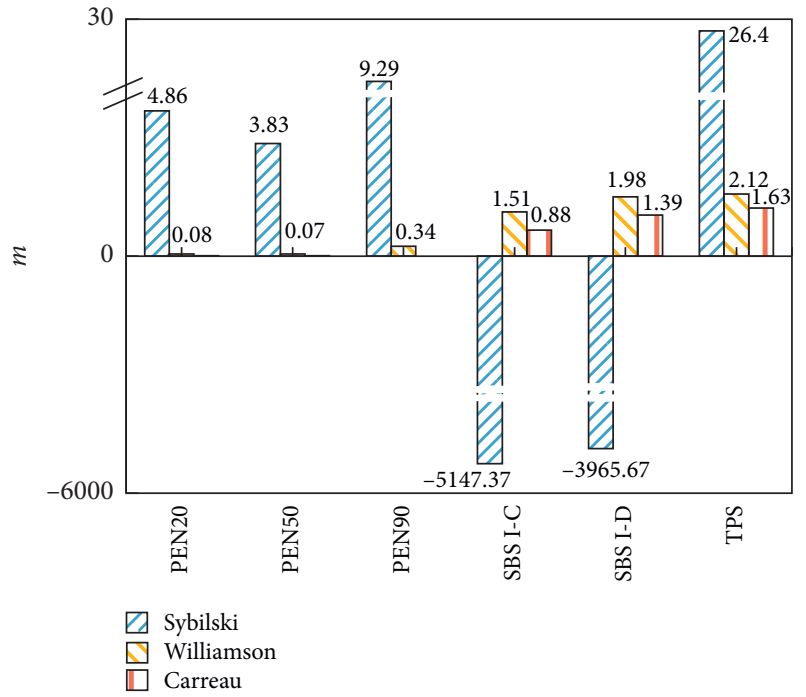

(c)

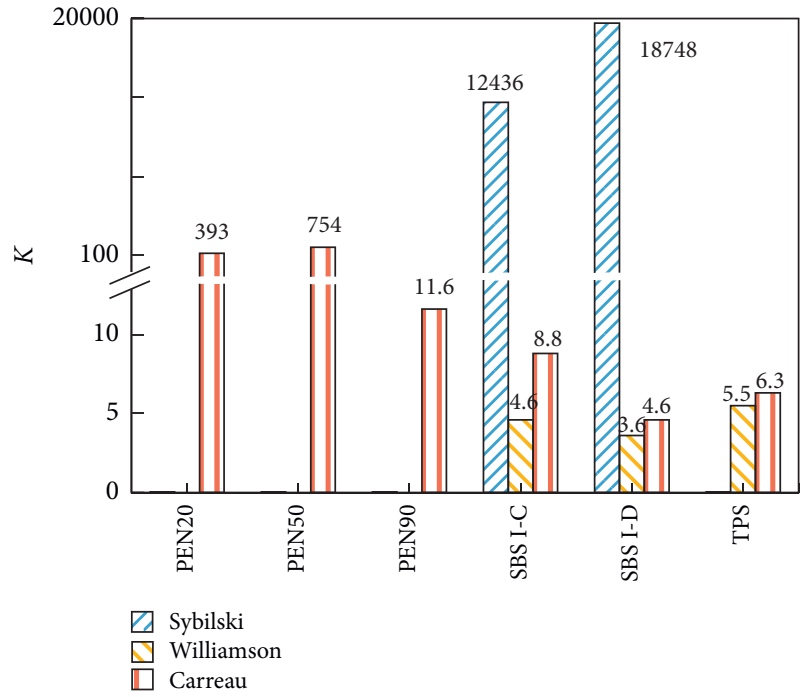

(b)

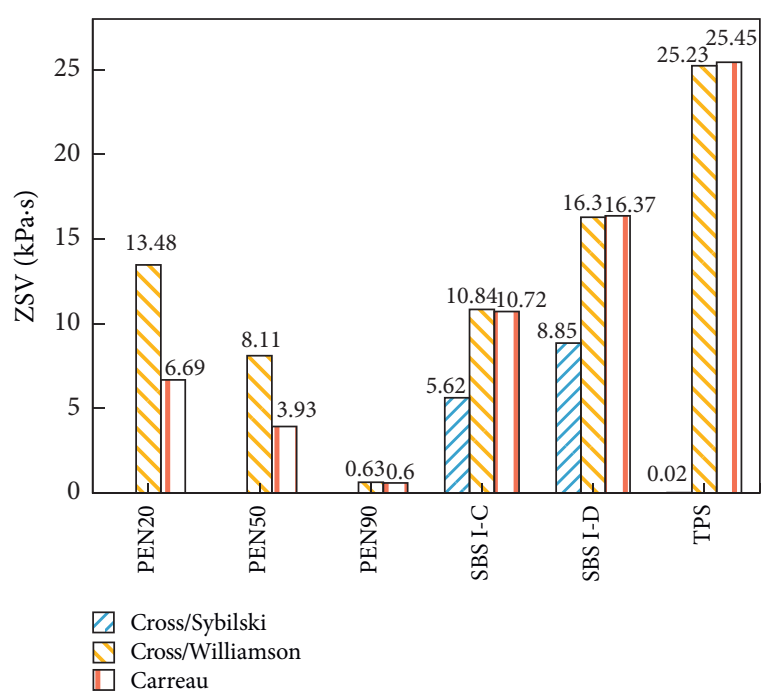

(d)

Figure 3: Zero-shear viscosity (ZSV) test results of six asphalt binders.

$K$ and $m$ values were to zero, the closer the property of the material was to Newtonian fluid based on the Cross/Sybilski model [38]. Thus, the large $m$ value indicated that the asphalt was sensitive to the shear frequency. As shown in Figure $3(\mathrm{~b})$, the $K$ value of SBS I-D-modified asphalt was the highest, which reflected that the SBS I-D-modified asphalt was more similar to the non-Newtonian fluid. Thus, it was necessary to adopt ZSV value to analyze the high-temperature performance.

Based on the fitted $m$ value from Cross/Williamson model in Figure 3(c), the viscosity values of the modified asphalt were more sensitive to the shearing frequency than those of the base asphalt. The TPS-modified asphalt had the most considerable $m$ value, indicating that the viscosity test result was most affected by the shear frequency. In the results of the SBS-modified asphalt, it was found that the fitted $m$ from the Cross/Sybilski model were negative values, which may be caused by the small range of the selected shear frequency in this study. As shown in in Figure 3(d), the ZSV value obtained by the Cross/Sybilski model fluctuated greatly between different types of asphalt; in particular, the standard errors of ZSV of the base asphalt binders were large. In order to distinguish the high-temperature performance of different asphalt by using ZSV test, it is necessary to perform relational analysis with the calculation results through three different calculation models.

In addition, it could be concluded that the SBS I-Dmodified asphalt performed best to resist high-temperature deformations, followed by the SBS I-C-modified asphalt, due to the large and harmonious ZSV value in three different models. The ZSV of the PEN90 asphalt was significantly less than the other five types of asphalt, which 
TABLE 4: Fitting $K, m$, and ZSV values in three ZSV models.

\begin{tabular}{|c|c|c|c|c|c|c|c|}
\hline \multicolumn{2}{|c|}{ Asphalt binders } & $K$ & $\sigma_{K}$ & $m$ & $\sigma_{m}$ & ZSV (kPa·s) & $\sigma_{\mathrm{ZSV}}(\mathrm{kPa} \cdot \mathrm{s})$ \\
\hline \multirow{3}{*}{ PEN20 } & Sybilski & $5.06 \times 10^{-4}$ & $2.33 \times 10^{-12}$ & 4.86 & 4.54 & 1.71 & 80.4 \\
\hline & Williamson & $2.21 \times 10^{-6}$ & $7.97 \times 10^{-10}$ & 0.08 & 0.06 & 13483.06 & 4521.4 \\
\hline & Carreau & 392.95 & 297.34 & $6.04 \times 10^{-4}$ & $2.07 \times 10^{-3}$ & 6694.85 & 424.38 \\
\hline \multirow{3}{*}{ PEN50 } & Sybilski & $1.56 \times 10^{-3}$ & 4.67 & 3.83 & 1.11 & 1.56 & 46.74 \\
\hline & Williamson & $1.45 \times 10^{-6}$ & $5.35 \times 10^{-9}$ & 0.07 & 0.06 & 8106.44 & 3400.58 \\
\hline & Carreau & 753.61 & 195.47 & $7.83 \times 10^{-4}$ & $2 \times 10^{-3}$ & 3926.12 & 812.54 \\
\hline \multirow{3}{*}{ PEN90 } & Sybilski & $3.3 \times 10^{-3}$ & $3.89 \times 10^{-2}$ & 9.29 & 2.93 & 2.08 & 10.24 \\
\hline & Williamson & $8.62 \times 10^{-9}$ & $1.41 \times 10^{-11}$ & 0.34 & 0.25 & 630.81 & 36.71 \\
\hline & Carreau & 11.63 & 8.16 & $1.44 \times 10^{-4}$ & $8.29 \times 10^{-3}$ & 599.17 & 8.32 \\
\hline \multirow{3}{*}{ SBS I-C } & Sybilski & 12435.68 & 0 & -5147.37 & 0 & 5622.27 & 704.7 \\
\hline & Williamson & 4.64 & 0.25 & 1.51 & 0.12 & 10841.59 & 183.54 \\
\hline & Carreau & 8.78 & 0.91 & 0.88 & 0.05 & 10718.52 & 108.85 \\
\hline \multirow{3}{*}{ SBS I-D } & Sybilski & 18747.94 & 0 & -3965.67 & 0 & 8845.34 & 1155.74 \\
\hline & Williamson & 3.59 & 0.18 & 1.98 & 0.18 & 16295.35 & 253.91 \\
\hline & Carreau & 4.62 & 0.73 & 1.39 & 0.14 & 16365.79 & 220.56 \\
\hline \multirow{3}{*}{ TPS } & Sybilski & 0.02 & 0 & 26.44 & 0 & 17.46 & 2.92 \\
\hline & Williamson & 5.45 & 0.43 & 2.12 & 0.31 & 25233.52 & 729.53 \\
\hline & Carreau & 6.28 & 1.71 & 1.63 & 0.28 & 25453.75 & 670.56 \\
\hline
\end{tabular}

was similar to the MSCR and DSR test results. Thus, the PEN90 asphalt performance was significantly softviscoelastic.

In summary, for the SBS-modified asphalt with high viscosity, the high-temperature performance could be well characterized by using three ZSV models, of which the results coincided with each other. Meanwhile, for the asphalt with low viscosity but large complex modulus $G^{*}$ (such as the low-grade PEN20 asphalt) and the asphalt with especially high viscosity (such as TPS-modified asphalt), the ZSV value by one ZSV model did not reflect their low stress sensitivity and good rutting resistance. This result was consistent with the results of previous studies [16].

4.2. High-Temperature Properties of Asphalt Mixtures. As shown in Table 5, the dynamic stability (DS) of the TPSmodified asphalt mixture was 9965 times/mm, while the DS of SBS I-D, PEN20, SBS I-C, PEN50, and PEN90 asphalt mixture were $8150,5415,4603,1986$, and 580 times $/ \mathrm{mm}$, respectively. The DS results concluded that the TPS-modified asphalt mixture performed best for resisting the rutting deformations.

4.3. GRA for the Technical Indexes. In order to comprehensively analyze the high-temperature performance of the asphalt and its mixtures, the high-temperature performance technical indexes were normalized based on the maximum test values of the different series, as shown in equation (14). It is worth noting that the DSR and MSCR data were all at the temperature of $64^{\circ} \mathrm{C}$. Aiming to ensure the reliability of the conclusions, DSR data were also obtained from the RTFOT residue of asphalt binders to study the correlation between rutting factor and dynamic stability under different experimental conditions.
TABLE 5: Rutting testing data of six asphalt mixtures.

\begin{tabular}{lcccccc}
\hline & \multicolumn{3}{c}{ Unmodified } & \multicolumn{3}{c}{ Modified } \\
Parameters & PEN20 & PEN50 & PEN90 & $\begin{array}{c}\text { SBS I- } \\
\text { C }\end{array}$ & $\begin{array}{c}\text { SBS I- } \\
\text { D }\end{array}$ & TPS \\
\hline $\begin{array}{l}\text { DS, times/ } \\
\text { mm }\end{array}$ & 5415 & 1986 & 580 & 4603 & 8150 & 9965 \\
$\sigma$, times $/ \mathrm{mm}$ & 601.1 & 186.7 & 45.8 & 580 & 1352.9 & 1135.3 \\
\hline
\end{tabular}

$\sigma$ denotes the standard deviation.

$$
\text { Normalized } x_{i}(k)=\frac{x_{i}(k)}{x_{\max }(k)},
$$

where $x$ was the technical index, such as softening point, viscosity, rutting indicator, $R$, and ZSV. $k$ was the type of the asphalt binders, which includes the unmodified asphalt and modified asphalt.

As shown in Figure 4, the normalized high-temperature performance technical indexes of the asphalt were drawn in hexagonal envelope diagram. The asphalt with the largest hexagonal envelope area should have the best high-temperature overall performance. Thus, the high-temperature performance ranking of the asphalt was TPS-modified asphalt, followed by SBS I-D, SBS I-C, PEN20, PEN50, and PEN90. The presented analysis results had a good match with the viscosity at $60^{\circ} \mathrm{C}$ and the Carreau modeled ZSV test, while they were different from the traditional DSR and MSCR results. In general, the modified asphalt performed better than the unmodified asphalt according to the hightemperature rheological properties tests. Despite the excellent performance in some test results, such as the low deformation in MSCR, the hexagonal envelope area analysis showed that the PEN20 asphalt presented the unbalanced high-temperature performance.

Besides, in the previous research, dynamic stability (DS) was a useful indicator to characterize the high-temperature 


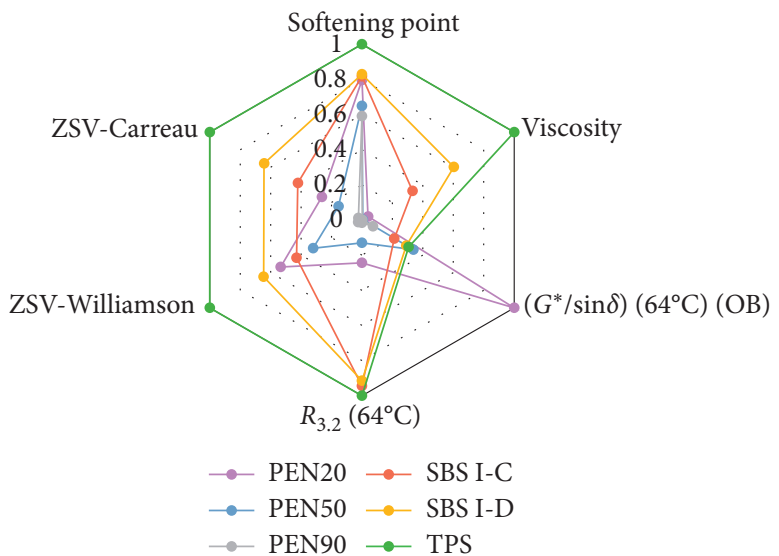

FIGURE 4: High-temperature performance distributions of six asphalt binders in hexagonal envelope diagram.

TABLE 6: Data preprocessing for GRA.

\begin{tabular}{|c|c|c|c|c|c|c|c|}
\hline \multirow{2}{*}{ Parameters } & \multirow{2}{*}{$X_{m}$} & \multicolumn{3}{|c|}{ Unmodified } & \multicolumn{3}{|c|}{ Modified } \\
\hline & & PEN20 & PEN50 & PEN90 & SBS I-C & SBS I-D & TPS \\
\hline \multicolumn{8}{|l|}{ Original sequence } \\
\hline DS (times/mm) & $X_{0}^{(0)}$ & 5415 & 1986 & 580 & 4603 & 8150 & 9965 \\
\hline Penetration $\left(25^{\circ} \mathrm{C}\right)(0.1 \mathrm{~mm})$ & $X_{1}^{(0)}$ & 23 & 54 & 91 & 74 & 57 & 69 \\
\hline Softening point $\left({ }^{\circ} \mathrm{C}\right)$ & $X_{2}^{(0)}$ & 64.2 & 52.4 & 47.7 & 66 & 66.9 & 80.7 \\
\hline Viscosity $\left(60^{\circ} \mathrm{C}\right)(\mathrm{Pa} \cdot \mathrm{s})$ & $X_{3}^{(0)}$ & 3315 & 394 & 198 & 27360 & 49755 & 82459 \\
\hline$\left(G^{*} / \sin \delta\right)\left(64^{\circ} \mathrm{C}\right)(\mathrm{OB})$ & $X_{4}^{(0)}$ & 15.11 & 5.09 & 1.09 & 3.20 & 4.40 & 4.63 \\
\hline$\left(G^{*} / 1-(\sin \delta \cdot \tan \delta)^{-1}\right)\left(64^{\circ} \mathrm{C}\right)(\mathrm{OB})$ & $X_{5}^{(0)}$ & 18.94 & 5.75 & 1.21 & 5.95 & 9.4 & 10.30 \\
\hline$J_{\mathrm{nr} 3.2}\left(\mathrm{kPa}^{-1}\right)\left(64^{\circ} \mathrm{C}\right)$ & $X_{6}^{(0)}$ & 0.2391 & 1.3976 & 3.43 & 0.3328 & 0.1369 & 0.0473 \\
\hline$J_{\mathrm{nr} 0.1}\left(\mathrm{kPa}^{-1}\right)\left(64^{\circ} \mathrm{C}\right)$ & $X_{7}^{(0)}$ & 0.2009 & 1.0635 & 2.175 & 0.0389 & 0.0297 & 0.0046 \\
\hline$R_{3.2}(\%)\left(64^{\circ} \mathrm{C}\right)$ & $X_{8}^{(0)}$ & 23.6 & 12.6 & 1.5 & 91.3 & 88.4 & 96.7 \\
\hline$R_{0.1}(\%)\left(64^{\circ} \mathrm{C}\right)$ & $X_{9}^{(0)}$ & 32.3 & 25.7 & 20.8 & 94.3 & 97.3 & 99.6 \\
\hline ZSV-Sybilski (Pa.s) & $X_{10}^{(0)}$ & 1.71 & 1.56 & 2.08 & 5622.27 & 8845.34 & 17.46 \\
\hline ZSV-Williamson (Pa.s) & $X_{11}^{(0)}$ & 13483.1 & 8106.44 & 630.81 & 10841.6 & 16295.4 & 25233.5 \\
\hline ZSV-Carreau (Pa.s) & $X_{12}^{(0)}$ & 6694.85 & 3926.12 & 599.17 & 10718.5 & 16365.8 & 25453.8 \\
\hline$\left(G^{*} / \sin \delta\right)\left(64^{\circ} \mathrm{C}\right)(\mathrm{RTFOT})$ & $X_{13}^{(0)}$ & 27.59 & 8.81 & 1.98 & 5.20 & 6.85 & 5.87 \\
\hline \multicolumn{8}{|l|}{ Normalized sequence } \\
\hline DS (times/mm) & $X_{0}^{(1)}$ & 1.06 & 0.39 & 0.11 & 0.90 & 1.59 & 1.95 \\
\hline Penetration $\left(25^{\circ} \mathrm{C}\right)(0.1 \mathrm{~mm})$ & $X_{1}^{(1)}$ & 0.38 & 0.88 & 1.48 & 1.21 & 0.93 & 1.13 \\
\hline Softening point $\left({ }^{\circ} \mathrm{C}\right)$ & $X_{2}^{(1)}$ & 1.02 & 0.83 & 0.76 & 1.05 & 1.06 & 1.28 \\
\hline Viscosity $\left(60^{\circ} \mathrm{C}\right)(\mathrm{Pa} \cdot \mathrm{s})$ & $X_{3}^{(1)}$ & 0.12 & 0.01 & 0.01 & 1.00 & 1.83 & 3.03 \\
\hline$\left(G^{*} / \sin \delta\right)\left(64^{\circ} \mathrm{C}\right)$ & $X_{4}^{(1)}$ & 2.71 & 0.91 & 0.20 & 0.57 & 0.79 & 0.83 \\
\hline$\left(G^{*} / 1-(\sin \delta \cdot \tan \delta)^{-1}\right)\left(64^{\circ} \mathrm{C}\right)$ & $X_{5}^{(1)}$ & 2.20 & 0.67 & 0.14 & 0.69 & 1.10 & 1.20 \\
\hline$J_{\mathrm{nr} 3.2}\left(\mathrm{kPa}^{-1}\right)\left(64^{\circ} \mathrm{C}\right)$ & $X_{6}^{(1)}$ & 0.26 & 1.50 & 3.69 & 0.36 & 0.15 & 0.05 \\
\hline$J_{\mathrm{nr} 0.1}\left(\mathrm{kPa}^{-1}\right)\left(64^{\circ} \mathrm{C}\right)$ & $X_{7}^{(1)}$ & 0.34 & 1.82 & 3.72 & 0.07 & 0.05 & 0.01 \\
\hline$R_{3.2}(\%)\left(64^{\circ} \mathrm{C}\right)$ & $X_{8}^{(1)}$ & 0.45 & 0.24 & 0.03 & 1.74 & 1.69 & 1.85 \\
\hline$R_{0.1}(\%)\left(64^{\circ} \mathrm{C}\right)$ & $X_{9}^{(1)}$ & 0.52 & 0.42 & 0.34 & 1.53 & 1.58 & 1.62 \\
\hline ZSV-Sybilski (Pa·s) & $X_{10}^{(1)}$ & 0.00 & 0.00 & 0.00 & 2.33 & 3.66 & 0.01 \\
\hline ZSV-Williamson (Pa.s) & $X_{11}^{(1)}$ & 1.08 & 0.65 & 0.05 & 0.87 & 1.31 & 2.03 \\
\hline ZSV-Carreau (Pa·s) & $X_{12}^{(1)}$ & 0.63 & 0.37 & 0.06 & 1.01 & 1.54 & 2.40 \\
\hline$\left(G^{*} / \sin \delta\right)\left(64^{\circ} \mathrm{C}\right)(\mathrm{RTFOT})$ & $X_{13}^{(1)}$ & 2.94 & 0.94 & 0.21 & 0.55 & 0.73 & 0.63 \\
\hline
\end{tabular}


TABLE 7: Gray relational coefficients between asphalt indexes and dynamic stability.

\begin{tabular}{|c|c|c|c|c|c|c|c|}
\hline \multirow{2}{*}{ Parameters } & \multicolumn{3}{|c|}{ Unmodified } & \multicolumn{3}{|c|}{ Modified } & \multirow{2}{*}{ Gray relational degree } \\
\hline & PEN20 & PEN50 & PEN90 & SBS I-C & SBS I-D & TPS & \\
\hline$\gamma_{1}$ & 0.52 & 0.61 & 0.35 & 0.72 & 0.53 & 0.48 & 0.53 \\
\hline$\gamma_{2}$ & 0.97 & 0.63 & 0.54 & 0.85 & 0.59 & 0.53 & 0.68 \\
\hline$\gamma_{3}$ & 0.44 & 0.67 & 0.89 & 0.89 & 0.77 & 0.41 & 0.68 \\
\hline$\gamma_{4}$ & 0.31 & 0.59 & 0.92 & 0.70 & 0.48 & 0.40 & 0.57 \\
\hline$\gamma_{5}$ & 0.39 & 0.73 & 0.98 & 0.79 & 0.60 & 0.50 & 0.67 \\
\hline$\gamma_{6}$ & 0.48 & 0.40 & 0.17 & 0.58 & 0.34 & 0.28 & 0.38 \\
\hline$\gamma_{7}$ & 0.51 & 0.34 & 0.17 & 0.47 & 0.33 & 0.28 & 0.35 \\
\hline$\gamma_{8}$ & 0.55 & 0.85 & 0.91 & 0.47 & 0.90 & 0.90 & 0.76 \\
\hline$\gamma_{9}$ & 0.59 & 0.98 & 0.78 & 0.54 & 1.00 & 0.70 & 0.77 \\
\hline$\gamma_{10}$ & 0.41 & 0.66 & 0.88 & 0.34 & 0.26 & 0.28 & 0.47 \\
\hline$\gamma_{11}$ & 0.99 & 0.75 & 0.94 & 0.98 & 0.73 & 0.92 & 0.88 \\
\hline$\gamma_{12}$ & 0.64 & 1.00 & 0.95 & 0.89 & 0.95 & 0.63 & 0.84 \\
\hline$\gamma_{13}$ & 0.28 & 0.58 & 0.90 & 0.69 & 0.46 & 0.36 & 0.55 \\
\hline
\end{tabular}

performance of asphalt mixtures [39-41]. The DS ranking of the asphalt mixtures was TPS-modified asphalt, followed by SBS I-D, PEN20, SBS I-C, PEN50, and PEN90, which was also different from the result by the envelope area analysis.

In order to create the relationship between the performance evaluation indexes of the asphalt and the performance of the asphalt mixture, GRA was adopted and the results of different asphalt binders and asphalt mixtures were defined as $X_{m}^{(0)}$ (where $m=0,1,2, \ldots, 13$ ) and listed in Table 6. The DS of the asphalt mixture were selected for the main arrays, while the high-temperature performance indexes of asphalt were taken as the subarrays. In this section, the normalized results were calculated based on equations (6) and (7), as shown in Table 6.

In order to further analyze whether the rutting indicator $\left(G^{*} / \sin \delta\right)$ was the suitable candidate for the high-temperature performance evaluation of the asphalt, both the unaged samples (marked as OB) and RTFOT aged samples (marked as RTFOT) were analyzed in this part. In addition, the modified rutting indicator $\left(G^{*} / 1-(\sin \delta \cdot \tan \delta)^{-1}\right)$ was also introduced. The absolute difference between the two sequences was calculated, and then the gray relational coefficients and gray relational degree were calculated, based on equations (8) and (9). The detailed results are shown in Table 7.

The gray entropy relational degree was calculated by using equations (10) (13). Figure 5 shows the gray relational degree and entropy relational degree between asphalt binder indexes and dynamic stability of the corresponding asphalt mixtures. The gray relational degree was to take the arithmetic average of the gray relational coefficients of each type of asphalt, which would cause the loss of the tendency information of each local point. But the entropy relational degree could effectively evaluate the correlation on the entire sequence correlation degree rather than the influence of the single-point correlation coefficient. According to the entropy relational criterion, the larger the gray relational degree and entropy relational degree values of the hightemperature performance indexes were, the stronger the correlation between the high-temperature performance of the asphalt binder and the dynamic stability of asphalt

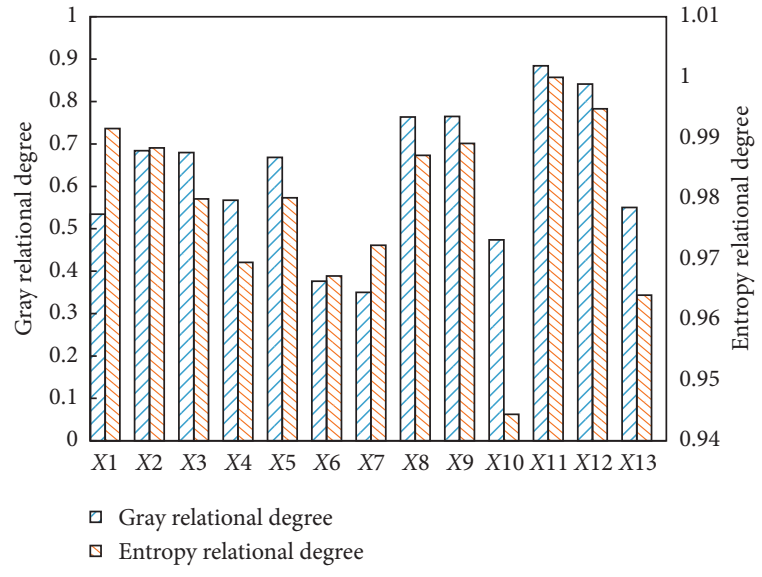

FIGURE 5: Gray relational degree and entropy relational degree between asphalt indexes and DS.

mixtures would be. For the gray relational degree, $\Gamma_{11}>\Gamma_{12}>\Gamma_{9}>\Gamma_{8}>\Gamma_{2}>\Gamma_{3}>\Gamma_{5}>\Gamma_{4}>\Gamma_{13}>\Gamma_{1}>\Gamma_{10}>\Gamma_{6}>\Gamma_{7}$, while, for the entropy relational degree, $E\left(X_{11}\right)>E\left(X_{12}\right)>E\left(X_{1}\right)>E\left(X_{9}\right)>E\left(X_{2}\right)>E\left(X_{8}\right)>E\left(X_{5}\right)$ $>E\left(X_{3}\right)>E\left(X_{7}\right)>E\left(X_{4}\right)>E\left(X_{6}\right)>E\left(X_{13}\right)>E\left(X_{10}\right)$. Although the two indicators were arranged in different rank order, the $X_{11}$ sequence, representing the Cross/Williamson modeled ZSV value, was the most relevant to the main array. Since the DS value would well reflect the hightemperature performance of the asphalt mixture, the ZSV test results fitted by the Cross/Williamson model had the highest correlation with the DS and would best characterize the high-temperature performance. The Cross/Williamson model was the most suitable for calculating and fitting the ZSV. Besides, it was found that the rutting indicator $\left(G^{*} / \sin \delta\right)$ of the unaged asphalt (named $\left.X_{4}\right)$ and the RTFOT asphalt (named $X_{13}$ ) had a similar trend, since the values of the gray relational degree were close. The results indicated that the correlation between the rutting indicator $\left(G^{*} / \sin \delta\right)$ in the asphalt's DSR tests and the DS value of asphalt mixture was very poor. The present rutting indicator for evaluating the asphalt mixtures' high-temperature performance might no longer be suitable. Although the 
correlation between the modified rutting factor (named $X_{5}$ ) and the DS value had improved, the accuracy of its evaluation was still lower than the MSCR and ZSV test results. However, the conclusion should be further proved based on more laboratory tests for the asphalt binder and its mixture.

\section{Conclusion}

Aiming to evaluate the relation between the high-temperature performance of the asphalt binders and their mixture, six typically used asphalt types were employed in this study. The DSR, MSCR, and ZSV tests were conducted on the asphalt binders, and the rutting tests were conducted on the asphalt mixture. Besides, to analyze the gray relational degree and entropy relational degree of the technical index, the correlation between the asphalt binder and the dynamic stability of the mixture was studied through the GRA method. Results in this paper provided a more systematic perspective for the further study of the high-temperature performance evaluation of asphalt binders.

Conclusions are listed as follows:

(1) In general, the modified asphalt performed better than the unmodified asphalt according to the hightemperature rheological properties tests. Despite the excellent performance in some test results, such as the lowest deformation in MSCR test, the hexagonal envelope area analysis showed that the PEN20 asphalt presented the unbalanced high-temperature performance.

(2) The ranking of the six kinds of asphalt binders from various tests was different. The TPS-modified asphalt performed best in the MSCR and ZSV tests, while the low-grade asphalt PEN20 had the best technical indexes in the DSR test.

(3) The Cross/Williamson model fitted zero-shear viscosity of the asphalt and the dynamic stability of the asphalt mixture had the highest gray relational degree and entropy relational degree, which indicated that the Cross/Williamson modeled ZSV value had the highest correlation with the DS value. Thus, the Cross/Williamson model was the most suitable for calculating and fitting the ZSV, which could be used as the key indicator of the high-temperature performance evaluation of the asphalt.

(4) Furthermore, according to the preliminary results on the six kinds of asphalt and its mixtures, the correlation between the rutting indicator in the asphalt's DSR tests and the DS value of asphalt mixture was very poor. The present rutting indicator $\left(G^{*} / \sin \delta\right.$ and $\left.G^{*} /\left(1-(\sin \delta \cdot \tan \delta)^{-1}\right)\right)$ for evaluating the asphalt mixtures' high-temperature performance might no longer be suitable. However, the conclusion should be further proved based on more laboratory tests for the asphalt binder and its mixture.

\section{Data Availability}

The data used to support the findings of this study are available from the corresponding author upon request.

\section{Conflicts of Interest}

The authors declare that there are no conflicts of interest regarding the publication of this paper.

\section{Acknowledgments}

The authors acknowledge the research funding by the Basic Scientific Research Foundation of Research Institute of Highway (no. 2020-9050), the National Natural Science Foundation of China (NSFC, no. 51908261), and the China Postdoctoral Science Foundation (no. 2020M670252).

\section{References}

[1] D. A. Anderson and T. W. Kennedy, "Development of SHRP binder specification," Journal of the Association of Asphalt Paving Technologists, vol. 62, pp. 481-507, 1993.

[2] M. Rahi, E. Fini, P. Hajikarimi, and F. M. Nejad, "Rutting characteristics of styrene-ethylene/propylene-styrene polymer modified asphalt," Journal of Materials in Civil Engineering, vol. 27, no. 4, Article ID 04014154, 2015.

[3] K. Yan, H. Xu, and L. You, "Rheological properties of asphalts modified by waste tire rubber and reclaimed low density polyethylene," Construction and Building Materials, vol. 83, pp. 143-149, 2015.

[4] L. You, Z. You, Q. Dai, and L. Zhang, "Assessment of nanoparticles dispersion in asphalt during bubble escaping and bursting: nano hydrated lime modified foamed asphalt," Construction and Building Materials, vol. 184, pp. 391-399, 2018.

[5] G. Zou, X. Zhang, and Z. Li, "Discussions on high temperature grading of Superpave PG system for asphalt binders," Central South Highway Engineering, vol. 29, no. 1, pp. 42-44, 2004.

[6] K. Yan, L. You, and D. Wang, "High-temperature performance of polymer-modified asphalt mixes: preliminary evaluation of the usefulness of standard technical index in polymer-modified asphalt," Polymers, vol. 11, no. 9, p. 1404, 2019.

[7] K. D. Stuart and W. S. Mogawer, "Validation of asphalt binder and mixture test that predict rutting susceptibility using FWHA ALF (with discussion)," Journal of the Association of Asphalt Paving Technologists, vol. 66, pp. 109-152, 1997.

[8] Z. Hu, H. Zhang, S. Wang, and T. Xu, "Thermal-oxidative aging mechanism of asphalt binder based on isothermal thermal analysis at the SARA level," Construction and Building Materials, vol. 255, Article ID 119349, 2020.

[9] X. Sheng, T. Xu, and M. Wang, "Preparation, shape memory performance and microstructures of emulsified asphalt modified by multi-walled carbon nanotubes," Construction and Building Materials, vol. 230, Article ID 116954, 2020.

[10] M. Guo and Y. Tan, "Interaction between asphalt and mineral fillers and its correlation to mastics' viscoelasticity," International Journal of Pavement Engineering, pp. 1-10, 2019.

[11] M. Guo, H. Liu, Y. Jiao et al., "Effect of WMA-RAP technology on pavement performance of asphalt mixture: a state-of-the- 
art review," Journal of Cleaner Production, vol. 266, Article ID 121704, 2020.

[12] A. Mo, "Refinement of the superpave specification parameter for performance grading of asphalt," Journal of Transportation Engineering, vol. 127, no. 5, pp. 357-362, 2001.

[13] A. Shenoy, "High temperature performance grading of asphalts through a specification criterion that could capture field performance," Journal of Transportation Engineering, vol. 130, no. 1, pp. 132-137, 2004.

[14] H. U. Bahia, D. I. Hanson, M. Zeng et al., Characterization of Modified Asphalt Binders in Superpave Mix Design. NCHRP Rep. No. 459, National Academy Press, Washington, DC, USA, 2001.

[15] J. D’Angelo, R. Kluttz, R. N. Dongre et al., "Revision of the superpave high temperature binder specification: the multiple stress creep recovery test," Journal of the Association of Asphalt Paving Technologists, vol. 76, pp. 123-162, 2007.

[16] J. D'Angelo, "The relationship of the MSCR test to rutting," Road Materials and Pavement Design, vol. 10, no. sup1, pp. 61-80, 2009.

[17] AASHTO, Standard Method of Test for Multiple Stress Creep Recovery (MSCR) Test of Asphalt Binder Using a Dynamic Shear Rheometer (DSR), American Association of State Highway and Transportation Officials, Washington, DC, USA, 2009.

[18] S. E. Zoorob, J. P. Castro-Gomes, L. A. Pereira Oliveira, and J. O'Connell, "Investigating the multiple stress creep recovery bitumen characterisation test," Construction and Building Materials, vol. 30, pp. 734-745, 2012.

[19] B. Singh, N. Saboo, and P. Kumar, "Effect of short-term aging on creep and recovery response of asphalt binders," Journal of Transportation Engineering, Part B: Pavements, vol. 143, no. 4, Article ID 04017017, 2017.

[20] E. DuBois, D. Y. Mehta, and A. Nolan, "Correlation between multiple stress creep recovery (MSCR) results and polymer modification of binder," Construction and Building Materials, vol. 65, pp. 184-190, 2014.

[21] N. Saboo, R. Kumar, P. Kumar, and A. Gupta, "Ranking the rheological response of SBS-and EVA-modified bitumen using MSCR and LAS tests," Journal of Materials in Civil Engineering, vol. 30, no. 8, Article ID 04018165, 2018.

[22] A. Golalipour, H. U. Bahia, and H. A. Tabatabaee, "Critical considerations toward better implementation of the multiple stress creep and recovery test," Journal of Materials in Civil Engineering, vol. 29, no. 5, Article ID 04016295, 2017.

[23] A. V. Kataware and D. Singh, "A study on rutting susceptibility of asphalt binders at high stresses using MSCR test," Innovative Infrastructure Solutions, vol. 2, no. 1, p. 4, 2017.

[24] D. Sybilski, "Zero-shear viscosity of bituminous binder and its relation to bituminous mixture's rutting resistance," Transportation Research Record: Journal of the Transportation Research Board, vol. 1535, no. 1, pp. 15-21, 1996.

[25] M. A. Notani and M. Mokhtarnejad, "Investigating the rheological and self-healing capability of toner-modified asphalt binder," Proceedings of the Institution of Civil EngineersConstruction Materials, vol. 173, no. 3, pp. 123-131, 2020.

[26] N. Saboo and P. Kumar, "Analysis of different test methods for quantifying rutting susceptibility of asphalt binders," Journal of Materials in Civil Engineering, vol. 28, no. 7, Article ID 04016024, 2016.

[27] R. Romera, A. Santamaría, J. J. Peña et al., "Rheological aspects of the rejuvenation of aged bitumen," Rheologica Acta, vol. 45, no. 4, pp. 474-478, 2006.
[28] P. Muñoz, Z. Liu, F. Yan, and K. Liao, "Application of grey system theory in studying asphalt aging," Petroleum Science and Technology, vol. 20, no. 9-10, pp. 939-949, 2002.

[29] C.-M. Wu, C.-C. Lee, J.-C. Du, and D.-H. Shen, "Development of acoustical prediction model for asphalt pavements using grey system approach," Road Materials and Pavement Design, vol. 11, no. 4, pp. 783-805, 2010.

[30] D. Zhang, M. Chen, S. Wu, J. Liu, and S. Amirkhanian, "Analysis of the relationships between waste cooking oil qualities and rejuvenated asphalt properties," Materials, vol. 10, no. 5, p. 508, 2017.

[31] J. Gao, H. Wang, Z. You, and X. Yang, "Gray relational entropy analysis of high temperature performance of bioasphalt binder and its mixture," International Journal of Pavement Research and Technology, vol. 11, pp. 698-708, 2018.

[32] China M, Technical Specification for Construction of Highway Asphalt Pavements, JTG F40-2004, China Communications Press, Beijing, China, 2004.

[33] AASHTO, Determining the Rheological Properties of Asphalt Binder Using a Dynamic Shear Rheometer (DSR), American Association of State Highway and Transportation Officials, Washington, DC, USA, 2010.

[34] AASHTO, Standard Method of Test for Effect of Heat and Air on a Moving Film of Asphalt Binder (Rolling Thin-Film Oven Test), American Association of State Highway and Transportation Officials, Washington, DC, USA, 2009.

[35] China M, Standard Test Methods of Bitumen and Bituminous Mixtures for Highway Engineering, JTG E20-2011, China Communications Press, Beijing, China, 2011.

[36] J. L. Deng, “Control problems of grey systems," Systems \& Control Letters, vol. 1, pp. 288-294, 1982.

[37] J. L. Deng, "Introduction to grey system theory," Journal of Grey System, vol. 1, pp. 1-24, 1989.

[38] D. Sybilski, "Non-Newtonian viscosity of polymer-modified bitumens," Materials and Structures, vol. 26, no. 1, pp. 15-23, 1993.

[39] H. Wang, Y. Bu, Y. Wang, X. Yang, and Z. You, "The effect of morphological characteristic of coarse aggregates measured with fractal dimension on asphalt mixture's high-temperature performance," Advances in Materials Science and Engineering, vol. 2016, Article ID 6264317, 2016.

[40] R. Zhang, H. Wang, J. Gao, Z. You, and X. Yang, "High temperature performance of SBS modified bio-asphalt," Construction and Building Materials, vol. 144, pp. 99-105, 2017.

[41] J. You, J. Wang, F. Xiao, S. Amirkhanian, J. Wang, and Z. Xu, "Impacts of multiple-polymer components on high temperature performance characteristics of airfield modified binders," Construction and Building Materials, vol. 134, pp. 694-702, 2017. 